\title{
World Health Organization "Roll Back Malaria" Campaign - Report on a visit to the Central Drug Research Institute, Lucknow, India
}

\author{
Maj AMJ Croft \\ MA,MSc,MBBS,MIL,DMCC,MFPHM,RAMC \\ Consultant in Public Health Medicine \\ HQ DSCA,St Giles' Court, 1-13 St Giles' High Street, London WC2 8LD
}

\section{Temporary Adviser to WHO - TDR/TDP}

\section{Background}

I visited the Central Drug Research Institute (CDRI) at Lucknow, India in the course of the annual scientific meeting of the Indian Pharmacological Society. This was held at CDRI between 18-20 December 1998. The meeting attracted some 450 delegates, many of whom came from overseas. The meeting was well organised, with sessions on neuro-, psycho-, cardiovascular, ocular and gastrointestinal pharmacology. There was a separate section on malaria prevention.

\section{Research at CDRI}

The research facilities of CDRI were much in evidence, and were highly impressive. CDRI is classified as a national laboratory, and is a multidisciplinary institute with an annual budget of US $\$ 3$ million. It has 14 research and development divisions, and employs approximately 1,000 scientists, research technicians and auxiliary staff. Its record of publications is outstanding. The institute has its own well-equipped laboratory animal centre, for Phase 1 trials. CDRI also has a ten-bedded clinical trials inpatient unit at the university hospital in Lucknow, which I visited.

CDRI was established in Lucknow in 1951, and has a proven capability to develop new pharmacological products, through all stages from initial conceptualisation to licensing. Over the past 20 years, CDRI has developed the following products, amongst others, which subsequently have been marketed:

- General products. Hypolipidaemic drug, cervical dilator, local anaesthetic, antithyroid agent, neuroleptic agent, neuromuscular blocking agent, antidepressant.

- Antimalarial products. a-B arteether (marketed as E-Mal), compound 80/53 (antirelapse antimalarial), malaria diagnostic kit, mosquito larvicide.

One of the keys to the scientific and commercial success of
CDRI lies in the fact that it has a particularly active Division of Clinical and Experimental Medicine, which is able to liaise at an early stage with pharmaceutical companies showing an interest in marketing products under development. The concentration of facilities on one site is also a strength of CDRI, and leads to shortened drug development times. It is notable that CDRI's artemisinin derivative is 5 years further ahead in its development cycle than WHO's own artemisininderived compound $(1,2)$.

\section{Conclusion}

I believe that as part of its "Roll Back Malaria" campaign, WHO should build partnerships with indigenous research institutes in tropical areas, such as CDRI, which have a proven track record of success in developing effective antimalarial products for local use. The main objective should be for WHO to support local scientific units of adequate size and expertise. According to circumstances the support might take one of various forms, such as equipment or development grants, consultancy advice, or bursaries to allow international travel.

Enlisting local research units in the "Roll Back Malaria" campaign would be an effective and cost effective strategy for WHO. In addition it would foster local scientific expertise, and would help to shift global resources from the wealthy north to the impoverished south.

\section{REFERENCES}

1. Asthana OP, Srivastava JS, Valecha N. Current status of the artemisinin derivatives in the treatment of malaria with focus on arteether. J Parasitic Diseases 1997; 21: 1-12.

2. Asthana OP, SRIVAstava JS, Pandey TK, et al. Clinical efficacy of arteether in complicated and uncomplicated $P$. falciparum malaria. Indian J Pharmacology 1997; 29: 34. 